\title{
COMPARISON OF STATISTICALLY CONTROLLED MACHINING SOLUTIONS OF TITANIUM ALLOYS USING USM
}

\author{
R. Singh \\ Department of Production Engineering \\ Guru Nanak Dev Engg. College, \\ Ludhiana-141006 (Punjab), India; \\ Phone: +91 98722 57575, Fax: +91 1612502700 \\ Email:rupindersingh78@yahoo.com
}

\begin{abstract}
The purpose of the present investigation is to compare the statistically controlled machining solution of titanium alloys using ultrasonic machining (USM). In this study, the previously developed Taguchi model for USM of titanium and its alloys has been investigated and compared. Relationships between the material removal rate, tool wear rate, surface roughness and other controllable machining parameters (power rating, tool type, slurry concentration, slurry type, slurry temperature and slurry size) have been deduced. The results of this study suggest that at the best settings of controllable machining parameters for titanium alloys (based upon the Taguchi design), the machining solution with USM is statistically controlled, which is not observed for other settings of input parameters on USM.
\end{abstract}

Keywords: ultrasonic machining; titanium alloys, Taguchi model, material removal rate, tool wear rate, surface roughness.

\section{INTRODUCTION}

The history of ultrasonic machining (USM) began with a paper by R.W. Wood and A.L. Loomis in 1927 (Singh and Khamba, 2006) and the first patent was granted to the American engineer Lewis Balamuth in 1945 (Singh, 2006). USM has been variously termed ultrasonic drilling, ultrasonic abrasive machining, ultrasonic cutting, ultrasonic dimensional machining, and slurry drilling (Singh and Khamba, 2006). However, from the early 1950s it was commonly known either as ultrasonic impact grinding or USM. The application of USM to the machining of hard and brittle material is well known, but hitherto less work has been reported for the machining of tough material. In the present work, the application of USM to tough materials has been explored. In this study titanium and its alloys has been selected based upon their industrial applications (Singh, 2006). These alloys are branded as difficult-to-machine materials but have high utility in manufacturing sector (Verma et al., 2003). They are alternatives for many engineering applications due to their superior properties (such as chemical inertness, high strength and stiffness at elevated temperatures, high strength to weight ratio, corrosion resistance, and oxidation resistance) (Singh and Khamba, 2003). The poor thermal conductivity of titanium alloys retards the dissipation of generated heat, creating instead a very high temperature at the tool work interface and adversely affecting the tool life and surface finish (Dornfeld et al., 1999; Singh and Khamba, 2009a). Titanium is chemically reactive at elevated temperatures and therefore the tool material either rapidly dissolves or chemically 
reacts during the traditional machining process, resulting in chipping, premature tool failure and poor surface finish (Verma et al., 2003). These properties also make titanium and its alloys difficult to machine into a precise size and shape (Singh and Khamba, 2004). As a result, their widespread applications have been hindered by the high cost of machining with current technology (Singh, 2006). So the conventional machining processes are unable to provide good machining characteristics to titanium alloys (Dornfeld, 1999). Therefore, there is a crucial need for reliable and cost-effective machining processes for titanium and its alloys (Singh and Khamba, 2007a). One of the cost-effective machining methods for titanium and its alloys is the electric discharge machining process (EDM) (Singh and Khamba, 2006). The material removal rate (MRR) is quite high using this process, however surface finish and dimensional accuracy are problematic (Benedict, 1987, Singh and Khamba, 2009a).

Now days another non-conventional machining process, USM has been successfully applied to the machining of titanium and its alloys (Thoe et al., 1998, Singh and Khamba, 2007b). But the volume of material removal in this process is quite less (Singh and Khamba, 2008). For stationary USM, an approach to model MRR, tool wear rate (TWR) and surface roughness (SR) has been proposed and applied for titanium and its alloys (Singh and Khamba, 2007b). In this Taguchi-based model for stationary USM, the macro modelling concept has been used. In a macro-model, the need to write a mathematical equation for developing relationships is bypassed (Singh and Khamba, 2009b, Taguchi and Konishi, 1987). The model developed is mechanistic in the sense that these parameters can be observed experimentally from a few experiments for a particular material and then used in the prediction of MRR, TWR and SR over a wide range of process parameters (Singh and Khamba, 2009b). This has been demonstrated for titanium and its alloys, where very good predictions have been obtained using an estimate of multi parameters. On the basis of this model, the relationships between the MRR, TWR, SR and the controlling machining parameters have been studied. These relationships agree well with the trends observed in experimental observations made by other investigators (Singh and Khamba, 2009a, Singh and Khamba, 2009b, Kumar et al., 2008, Kumar and Khamba, 2008). This model has been applied to predicting the MRR, TWR and SR for pure titanium, (ASTM Gr.2) and titanium alloy, (ASTM Gr.5). In this study the effect of six controllable parameters (tool material, slurry type, slurry concentration, grit size, slurry temperature, and power density) were examined, with titanium work piece as noise factor. Tables 1 and 2 illustrate the chemical composition of pure titanium, (ASTM Gr.2) and titanium alloy, (ASTM Gr.5) (Singh, 2006).

Table 1: Chemical analysis of pure Titanium (ASTM Gr.2)

\begin{tabular}{llllll}
\hline $\mathbf{C}$ & $\mathbf{H}$ & $\mathbf{N}$ & $\mathbf{O}$ & $\mathbf{F e}$ & $\mathbf{T i}$ \\
\hline 0.006 & 0.0007 & 0.014 & 0.140 & 0.05 & Balance \\
\hline
\end{tabular}

Table 2: Chemical analysis of Titanium alloy (ASTM Gr.5)

\begin{tabular}{llllllll}
\hline $\mathbf{C}$ & $\mathbf{H}$ & $\mathbf{N}$ & $\mathbf{O}$ & $\mathbf{A l}$ & $\mathbf{V}$ & $\mathbf{F e}$ & $\mathbf{T i}$ \\
\hline 0.019 & 0.0011 & 0.007 & 0.138 & 6.27 & 4.04 & 0.05 & Balance \\
\hline
\end{tabular}

Figure 1 shows the mechanism of tool wear in USM. The USM machine tool used for study was of $500 \mathrm{~W}$ capacity, which consists of an ultrasonic spindle kit, a constant pressure feed system and a slurry flow system (Singh, 2006). The ultrasonic 
spindle kit comprises an ultrasonic spindle, mounted with cylindrical horn of $\phi 25.4 \mathrm{~mm}$, a power supply unit. The power supply converts $50 \mathrm{~Hz}$ electrical supply to high frequency $20 \mathrm{kHz}$ AC output (Singh and Khamba, 2006). This was fed to the piezoelectric transducer located in the spindle. The transducer converts the electrical input into mechanical vibrations. The amplitude of vibrations was fixed in range of $0.0253-$ $0.0258 \mathrm{~mm}$ with a frequency of $20 \mathrm{kHz}+/-200 \mathrm{~Hz}$. The static load for the feed rate was fixed at $1.636 \mathrm{~kg}$ and the slurry flow rate at $26.4 \mathrm{~L} / \mathrm{min}$. The replaceable tools used for machining were solid tools made by silver brazing, having same area of cross-section, that is, $\varnothing 5 \mathrm{~mm}$. For this model, an L18 orthogonal array of Taguchi design (Phadke, 1989) was used to study the relationship between MRR, TWR, SR and the controllable machining parameters.

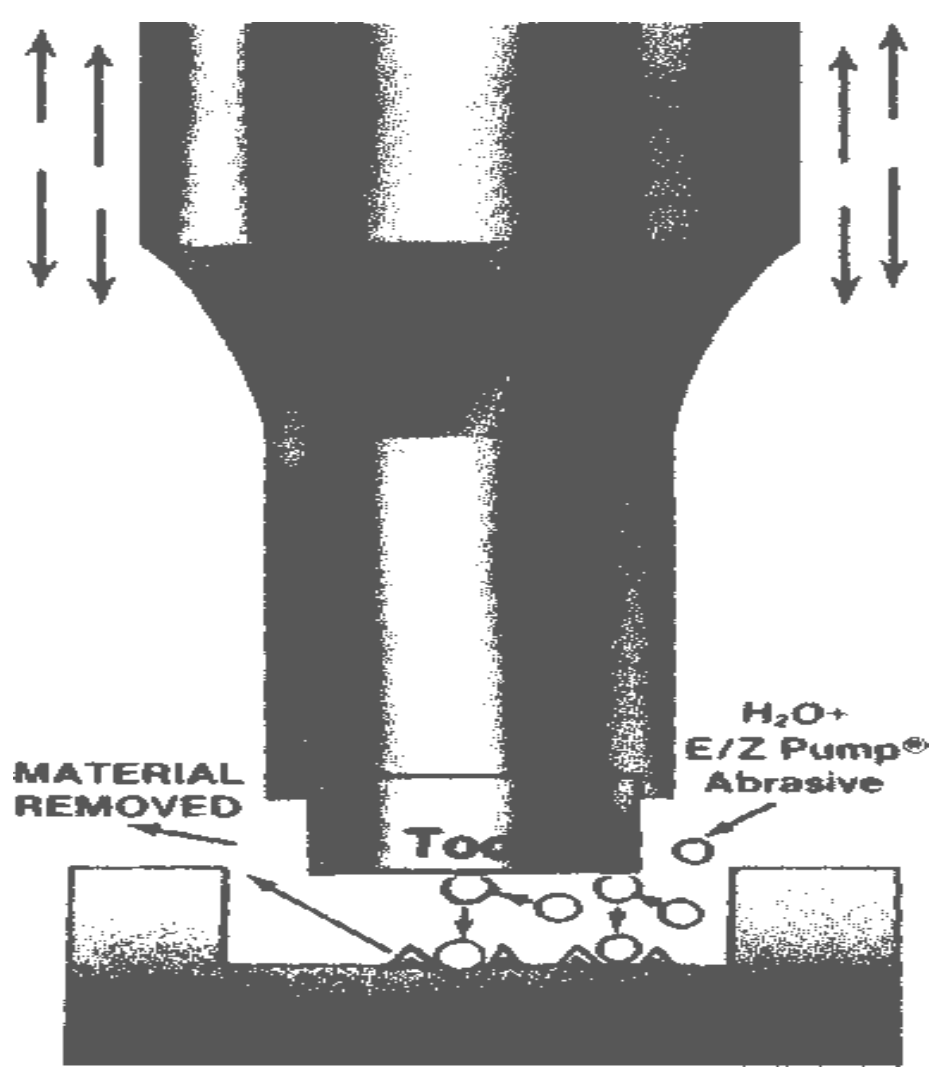

Figure 1: USM tool wear mechanisms (Singh and Khamba, 2006)

There are four sections in this paper. Following this Introduction, the design of experiment section describes the design of the experiments. In the third section, observations have been made to investigate whether the USM process for machining of titanium alloys is under statistical control as regards to MRR, TWR and SR is concerned. Conclusions are drawn in the last section, followed by references.

\section{DESIGN OF EXPERIMENTS}

The study presented in this paper is concerned primarily with obtaining the optimum system configuration with minimum expenditure of experimental resources. Table 3 shows different control variables and their levels. The best settings of the control factors were determined through experiments. For the analysis rd Expert ${ }^{\mathrm{TM}}$ software was used. The output parameter 
studied as response variables for analysis is shown in Table 4. The control log for experimentation is shown in Table 5.

Table 3: Control variables and their levels

\begin{tabular}{clccccccc}
\hline No & \multirow{2}{*}{$\begin{array}{c}\text { Control } \\
\text { variables }\end{array}$} & \multicolumn{8}{c}{ Levels of Control variables } \\
\cline { 3 - 8 } & L & L 1 & L 2 & L 3 & L 4 & L 5 & L 6 \\
\hline $\mathrm{A}$ & Tool & 6 & $\mathrm{SS}$ & $\mathrm{HSS}$ & $\mathrm{HCS}$ & $\mathrm{WC}$ & $\mathrm{Di}$ & $\mathrm{Ti}$ \\
$\mathrm{B}$ & Slurry conc. & 3 & $15 \%$ & $20 \%$ & $25 \%$ & - & - & - \\
$\mathrm{C}$ & Slurry type & 3 & $\mathrm{~B}_{4} \mathrm{C}$ & $\mathrm{Si}_{4} \mathrm{C}$ & $\mathrm{Al}_{2} \mathrm{O}_{3}$ & - & - & - \\
$\mathrm{D}$ & Slurry temp. & 3 & $10^{\circ} \mathrm{C}$ & $27^{\circ} \mathrm{C}$ & $60^{\circ} \mathrm{C}$ & - & - & - \\
$\mathrm{E}$ & Power rating & 3 & $150 \mathrm{~W}$ & $300 \mathrm{~W}$ & $450 \mathrm{~W}$ & - & - & - \\
F & Slurry size & 3 & 220 & 320 & 500 & - & - & - \\
\hline
\end{tabular}

Table 4: Response variable (output parameter) (Singh and Khamba, 2007b)

\begin{tabular}{lccc}
\hline Response No. & Response 1 & Response 2 & Response 3 \\
\hline Response name & MRR & TWR & S.R. \\
Response units & gm/min & gm/min & $\mu \mathrm{m}$ \\
Response type & Continuous & Continuous & Continuous \\
\hline
\end{tabular}

Table 5: Control log for experimentation

\begin{tabular}{lllllll}
\hline Exp. No. & \multicolumn{1}{c}{$\mathbf{B}$} & $\mathbf{C}$ & $\mathbf{D}$ & $\mathbf{E}$ & $\mathbf{F}$ \\
\hline 1 & $\mathrm{SS}$ & $15 \%$ & $\mathrm{~B}_{4} \mathrm{C}$ & $10^{\circ} \mathrm{C}$ & $150 \mathrm{~W}$ & 220 \\
2 & $\mathrm{SS}$ & $20 \%$ & $\mathrm{Si}_{4} \mathrm{C}$ & $27^{\circ} \mathrm{C}$ & $300 \mathrm{~W}$ & 320 \\
3 & $\mathrm{SS}$ & $25 \%$ & $\mathrm{Al}_{2} \mathrm{O}_{3}$ & $60^{\circ} \mathrm{C}$ & $450 \mathrm{~W}$ & 500 \\
4 & $\mathrm{HSS}$ & $15 \%$ & $\mathrm{~B}_{4} \mathrm{C}$ & $27^{\circ} \mathrm{C}$ & $300 \mathrm{~W}$ & 500 \\
5 & $\mathrm{HSS}$ & $20 \%$ & $\mathrm{Si}_{4} \mathrm{C}$ & $60^{\circ} \mathrm{C}$ & $450 \mathrm{~W}$ & 220 \\
6 & $\mathrm{HSS}$ & $25 \%$ & $\mathrm{Al}_{2} \mathrm{O}_{3}$ & $10^{\circ} \mathrm{C}$ & $150 \mathrm{~W}$ & 320 \\
7 & $\mathrm{HCS}$ & $15 \%$ & $\mathrm{Si}_{4} \mathrm{C}$ & $10^{\circ} \mathrm{C}$ & $450 \mathrm{~W}$ & 320 \\
8 & $\mathrm{HCS}$ & $20 \%$ & $\mathrm{Al}_{2} \mathrm{O}_{3}$ & $27^{\circ} \mathrm{C}$ & $150 \mathrm{~W}$ & 500 \\
9 & $\mathrm{HCS}$ & $25 \%$ & $\mathrm{~B}_{4} \mathrm{C}$ & $60^{\circ} \mathrm{C}$ & $300 \mathrm{~W}$ & 220 \\
10 & $\mathrm{WC}$ & $15 \%$ & $\mathrm{Al}_{2} \mathrm{O}_{3}$ & $60^{\circ} \mathrm{C}$ & $300 \mathrm{~W}$ & 320 \\
11 & $\mathrm{WC}$ & $20 \%$ & $\mathrm{~B}_{4} \mathrm{C}$ & $10^{\circ} \mathrm{C}$ & $450 \mathrm{~W}$ & 500 \\
12 & $\mathrm{WC}$ & $25 \%$ & $\mathrm{Si}_{4} \mathrm{C}$ & $27^{\circ} \mathrm{C}$ & $150 \mathrm{~W}$ & 220 \\
13 & $\mathrm{Di}$ & $15 \%$ & $\mathrm{Si}_{4} \mathrm{C}$ & $60^{\circ} \mathrm{C}$ & $150 \mathrm{~W}$ & 500 \\
14 & $\mathrm{Di}$ & $20 \%$ & $\mathrm{Al}_{2} \mathrm{O}_{3}$ & $10^{\circ} \mathrm{C}$ & $300 \mathrm{~W}$ & 220 \\
15 & $\mathrm{Di}$ & $25 \%$ & $\mathrm{~B}_{4} \mathrm{C}$ & $27^{\circ} \mathrm{C}$ & $450 \mathrm{~W}$ & 320 \\
16 & $\mathrm{Ti}$ & $15 \%$ & $\mathrm{Al}_{2} \mathrm{O}_{3}$ & $27^{\circ} \mathrm{C}$ & $450 \mathrm{~W}$ & 220 \\
17 & $\mathrm{Ti}$ & $20 \%$ & $\mathrm{~B}_{4} \mathrm{C}$ & $60^{\circ} \mathrm{C}$ & $150 \mathrm{~W}$ & 320 \\
18 & $\mathrm{Ti}$ & $25 \%$ & $\mathrm{Si}_{4} \mathrm{C}$ & $10^{\circ} \mathrm{C}$ & $300 \mathrm{~W}$ & 500 \\
\hline
\end{tabular}

For analysis of MRR, TWR, and SR, the signal to noise ratio (S/N) at different input parameters has been calculated (Figures 2-4). The ideal function selected here is nominally the best type. The best settings of USM for MRR are obtained using the SS tool, 450 Wpower rating with boron carbide slurry. This may be because the SS tool yields a better tool-work combination as regards to work-hardening: its higher power rating $(450 \mathrm{~W})$ imparts a higher momentum to the abrasive particles, and boron-carbide 
slurry is the hardest among the three slurries (Singh and Khamba, 2007b). As regards to TWR, the best settings of USM are obtained at $450 \mathrm{~W}$ power rating, with SS tool and 500 grit-size slurry. This may be explained on the basis that the ideal function selected was nominally the best type, so the SS tool and $450 \mathrm{~W}$ power rating ought to come. Also, the higher grit size (500 grit) must result in less TWR (Singh and Khamba, 2007b, Singh and Khamba, 2009b). For SR, slurry temperature is the most important, followed by slurry concentration and type of tool. Best settings are obtained at $25{ }^{\circ} \mathrm{C}$ at $25 \%$ concentration with SS tool. The selection of temperature and concentration setting may be explained on the basis that at this temperature and concentration neither sticking (because of freezing of slurry) nor evaporation took place, resulting in the maximum number of abrasive particles contributing in material removal mechanisms. The choice of SS tool is because of the selection of the ideal function as nominally the best type. Figures 5-7 show 'pie-charts' to understand the percentage contribution of each factor effect for MRR, TWR and SR. Based upon the proposed model for machining characteristics of titanium and its alloys using USM process, verification experiments were conducted under the optimum conditions and starting conditions of input parameters. The data agrees very well with the predictions about the improvement in the $\mathrm{S} / \mathrm{N}$ ratios and the deposition rate. Comparison of MRR, TWR and SR results obtained shows improvement by $52 \%, 7 \%$, and $32 \%$, respectively, even without introducing any other input. The present results are valid for the $90 \%-95 \%$ confidence interval.

A: Tool, B: Slurry conc., C: Slurry type, D: Slurry temp.,

E: Power rating, F: Slurry size

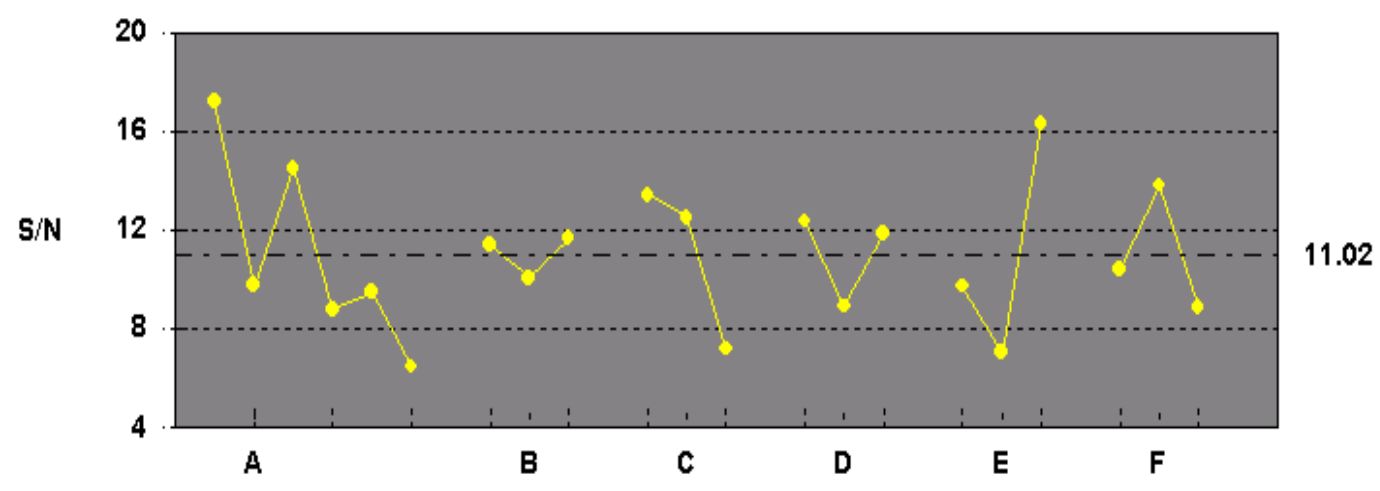

Figure 2: S/N responses of MRR vs input parameters (Singh and Khamba, 2007b)

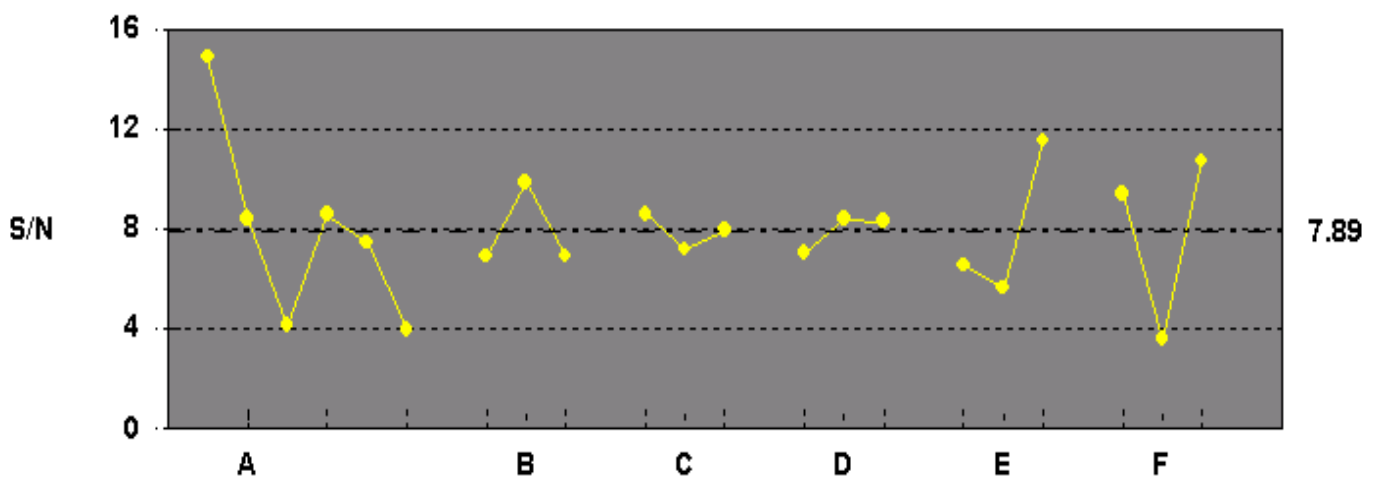

Figure 3: S/N responses of TWR vs input parameters (Singh and Khamba, 2007b) 




Figure 4: S/N responses of SR vs input parameters (Singh and Khamba, 2007b)

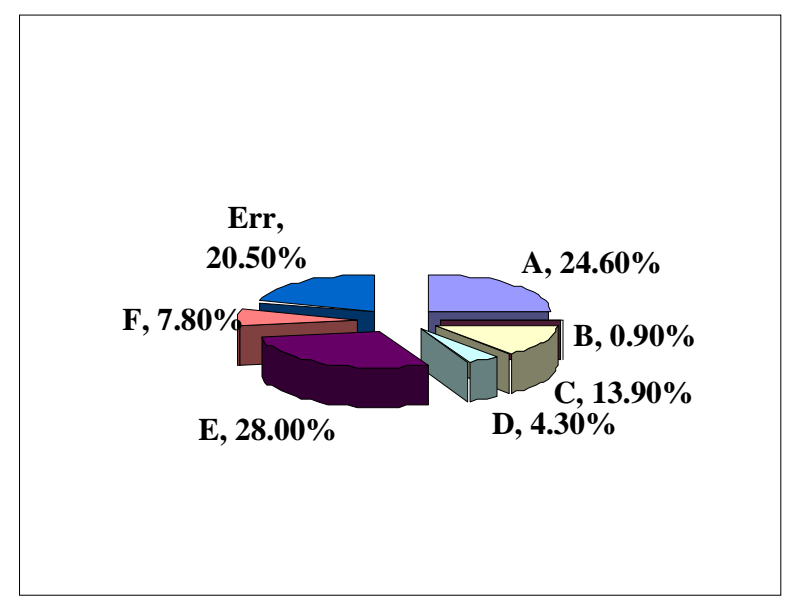

Figure 5: Pie chart of MRR (S/N) (Singh and Khamba, 2007b)

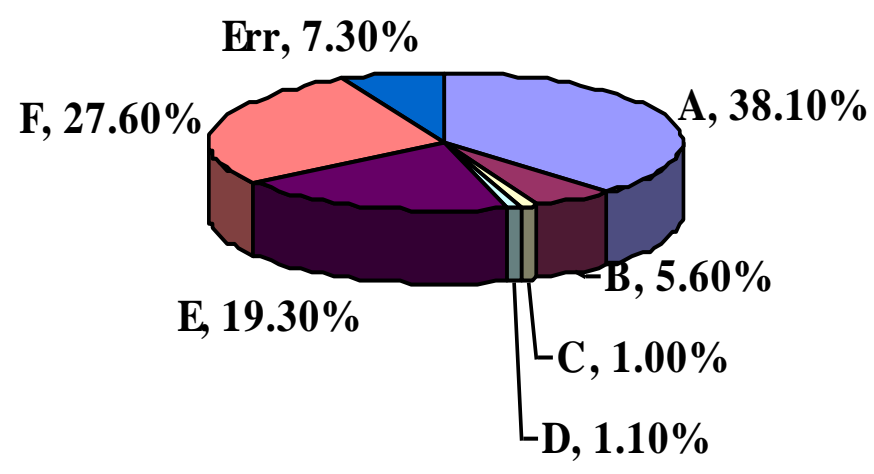

Figure 6: Pie chart of tool wear rate (S/N) (Singh and Khamba, 2007b)

The optimal results for MRR are obtained with SS tool at $450 \mathrm{~W}$ power rating with boron carbide slurry. The optimal results for TWR are obtained with SS tool at 450 $\mathrm{W}$ power rating and 500 grit size. The optimal results for SR are obtained at $25{ }^{\circ} \mathrm{C}$ temperature, with $25 \%$ concentration using SS tool. 


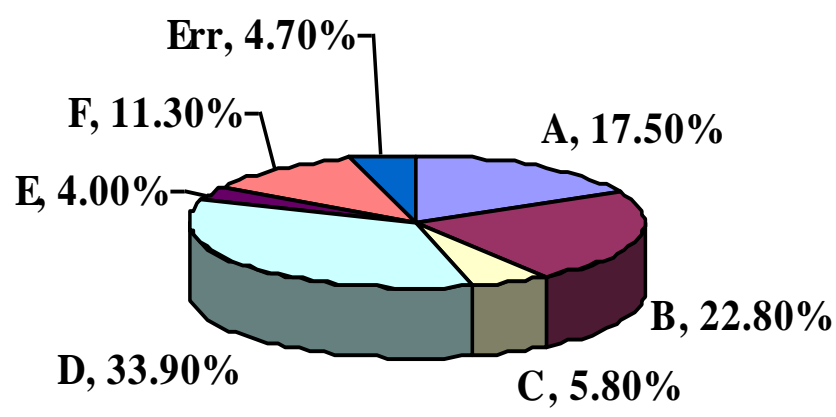

Figure 7: Pie chart of SR (S/N) (Singh and Khamba, 2007b)

\section{STATISTICAL ANALYSIS}

To understand whether the process (based on the Taguchi design model) is statistically controlled, 18 samples $\{6$ samples $\times 3$ (for each case of MRR/TWR/SR) $=18\}$ of titanium alloy work pieces were machined at the best settings of the input parameters for MRR (using SS tool at $450 \mathrm{~W}$ power rating with boron carbide slurry), TWR (using SS tool at $450 \mathrm{~W}$ power rating and 500 grit size), and SR (at $25^{\circ} \mathrm{C}$ slurry temperature, $25 \%$ concentration with SS tool) with USM. After calculation of MRR, TWR, and SR, the values obtained are shown in Table 6. Based upon the observations in Table 6, the run chart for calculated values of MRR, TWR and SR was developed (Figures 8-10). Now if the mean and standard deviation of a population that has the normal distribution is $\mu$ and $\sigma$ respectively then for variable data $\mathrm{X}$ the standard normal deviate $\mathrm{Z}$ is defined as (Devor et al., 2005):

$$
Z=\frac{X_{i}-\mu}{\sigma}
$$

where: $X_{i}$ is the variable data obtained, $\mu$ is the mean of data and $\sigma$ is the standard deviation.

Table 6: MRR, TWR and SR value at best settings of input parameters for USM

\begin{tabular}{llllll}
\hline \multirow{2}{z}{} & $\begin{array}{c}\text { Observations } \\
\text { MRR } \\
\dot{\boldsymbol{s}}\end{array}$ & $\begin{array}{l}\text { Observations } \\
\text { TWR }(\mathrm{gm} / \mathrm{min})\end{array}$ & $\begin{array}{l}\text { Observations } \\
\text { SR }(\mu \mathrm{m})\end{array}$ & $\begin{array}{l}\text { Above or below } \\
\text { MEAN }\end{array}$ & $\begin{array}{l}\text { Up or } \\
\text { Down }\end{array}$ \\
\hline 1 & 0.00500 & 0.00894 & 0.31 & $\mathrm{~B}$ & $\mathrm{D}$ \\
2 & 0.00498 & 0.00893 & 0.29 & $\mathrm{~B}$ & $\mathrm{U}$ \\
3 & 0.00499 & 0.00895 & 0.30 & $\mathrm{~B}$ & $\mathrm{U}$ \\
4 & 0.00502 & 0.00898 & 0.32 & $\mathrm{~A}$ & $\mathrm{U}$ \\
5 & 0.00503 & 0.00899 & 0.33 & $\mathrm{~A}$ & $\mathrm{U}$ \\
6 & 0.00509 & 0.00900 & 0.34 & $\mathrm{~A}$ & $\mathrm{U}$ and \\
Mean & 0.00501 & 0.008965 & 0.315 & $\mathrm{RUN}=1$ & $\mathrm{D}=1$ \\
\hline
\end{tabular}

$\mathrm{A}=$ above the mean, $\mathrm{B}=$ below the mean, $\mathrm{U}=$ up from previous reading, $\mathrm{D}=$ down from previous reading 


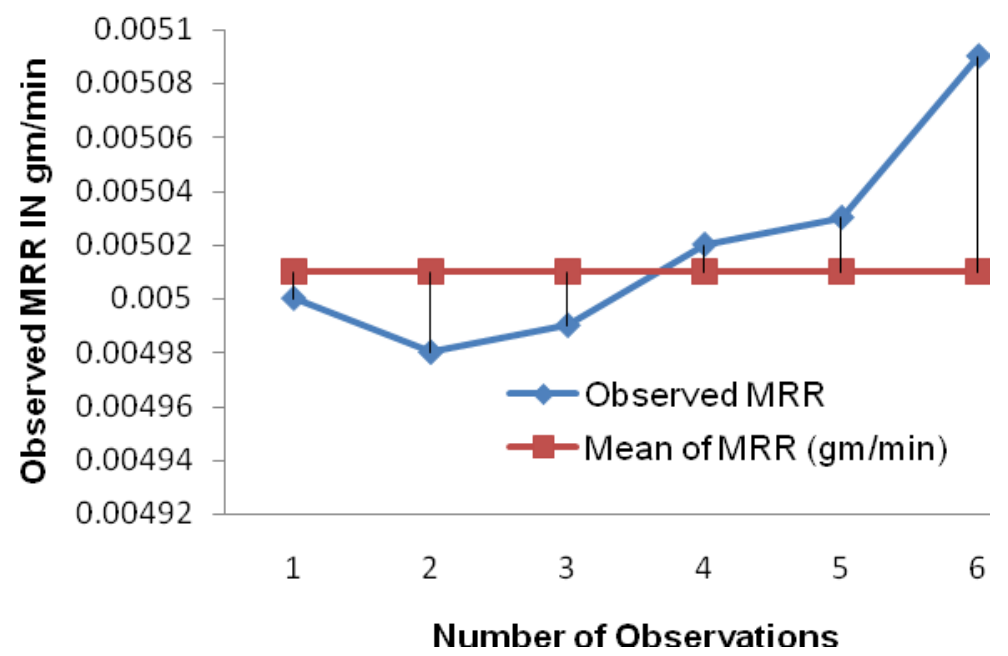

Figure 8: Run chart for calculated values of MRR



Figure 9: Run chart for calculated values of TWR

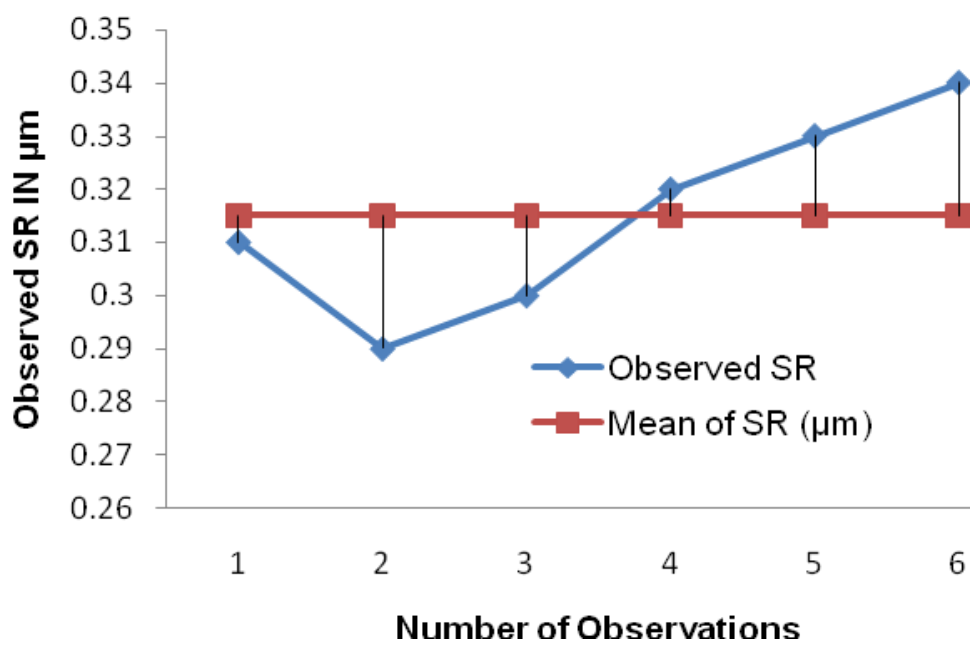

Figure 10: Run chart for calculated values of SR 
Calculation for Z (standard normal deviate) above and below:

$$
E(\text { run })_{A B}=\left(\frac{N}{2}+1\right)
$$

Where $N$ is the number of observations and $\mathrm{E}$ (run) AB $_{\mathrm{B}}$ is the expected number of runs above and below

$$
\begin{gathered}
E(\text { run })_{A B}=\left(\frac{6}{2}+1\right)=4 \\
\sigma_{A B}=\sqrt{N-\frac{1}{4}}
\end{gathered}
$$

Where $\sigma_{\mathrm{AB}}$ is the standard deviation of above and below

$$
\begin{gathered}
\sigma_{A B}=\sqrt{6-\frac{1}{4}}=1.118 \\
Z_{A B}=\left[\mathrm{RUN}_{\mathrm{AB}}-E(\text { run })_{A B}\right] / \sigma_{A B}
\end{gathered}
$$

Where $\mathrm{RUN}_{\mathrm{AB}}$ is the actual number of runs obtained above and below

$$
\begin{gathered}
Z_{A B}=\frac{(1-4)}{1.118}=-2.6834 \\
\left|Z_{\mathrm{AB}}\right|=2.6834 \\
E(\text { run })_{U D}=2 \times N-\frac{1}{3}=3.667
\end{gathered}
$$

Where $\mathrm{N}$ is the number of observations and $\mathrm{E}$ (run) $)_{\mathrm{UD}}$ is the expected number of runs up and down.

$$
\begin{gathered}
E(\text { run })_{U D}=2 \times 6-\frac{1}{3}=3.667 \\
\sigma_{U D}=\sqrt{16 \times N-29 \times 90}
\end{gathered}
$$

Where $\sigma_{\mathrm{UD}}$ is the standard deviation for up and down

$$
\begin{gathered}
\sigma_{U D}=\sqrt{16 \times 6-29 \times 90} \\
\sigma_{U D}=0.8628 \\
Z_{U D}=\left\{R_{U D}-E(\text { run })_{U D}\right\} / \sigma_{U D} \\
Z_{U D}=(1-3.667) / 0.8628 \\
Z_{U D}=-3.091 \\
\left|Z_{U D}\right|=3.091
\end{gathered}
$$

The critical value of $\mathrm{Z}$ is obtained by using Microsoft Excel software.

$$
Z_{c r i t}=\operatorname{NORMSINV}(1-\alpha / 2)
$$


Normally decision making is done with a certain margin of error ' $\alpha$ ' and taken as equal to 0.05 , that is, that there can be $5 \%$ chances of arriving at a wrong conclusion.

$$
\text { Therefore, } Z_{\text {crit }}=1.959963
$$

Now for decision making:

If $\left|Z_{A B}\right|>Z_{c r i t}$ OR /and $\left|Z_{U D}\right|>Z_{c r i t}$, then a non-random pattern exists.

In the present case, $\left|Z_{A B}\right|$ and $\left|Z_{U D}\right|$ are $>Z_{\text {crit }}$, which indicates the existence of a non random pattern. Now the exercise of predicting various statistical properties or drawing conclusions should not be undertaken unless the normality of distribution has been verified. Even if one has a large data, superimposing of normal curve on the histogram it is more difficult task than may be imagined. For a histogram, one requires a minimum of 50 observations, however the more the better and for assessing whether the underlying distribution is normal or not it becomes more difficult when the number of observations is fewer. For cumulative probability plot $(P i)$ :

$$
P i=\frac{S . N-0.5}{N}
$$

where S.N is the serial number of the data observation arranged in ascending order, and $N$ is the total number of observations in the data set. If the standard normal deviate follows the normal distribution that has mean $\mu=0$ and standard deviation $\sigma=1$, then

$$
f(Z)=\frac{1}{\sqrt{2 \Pi e^{\frac{Z^{2}}{2}}}}
$$

Equation 21 follows the normal probability curve and any data close to it also follows normal probability curve. The values of the standard normal deviates were calculated using cumulative probability and the dimensional values were arranged in ascending order as shown in Table 7. Based on Table 7, a normal probability curve was drawn to predict the probability as shown in Figures 11-13. As observed in Figure 5, the aforesaid data follows a non random pattern and is under the normal probability curve. So, there are very strong chances that the process is under statistical control however X-bar chart and R-bar chart cannot be drawn due to the small number of observational data points.

Table 7: Standard normal deviates and response variable (MRR, TWR, SR) in ascending order

\begin{tabular}{lrrrrr}
\hline $\begin{array}{l}\text { S. } \\
\text { No }\end{array}$ & $\begin{array}{c}\text { Pi } \\
\text { (Cumulative } \\
\text { Probability) }\end{array}$ & $\begin{array}{c}\text { (Standard normal } \\
\text { deviate) }\end{array}$ & $\begin{array}{c}\text { MRR value } \\
\text { in gm/min }\end{array}$ & $\begin{array}{c}\text { TWR value } \\
\text { in gm/min }\end{array}$ & $\begin{array}{c}\text { SR value } \\
\text { in } \boldsymbol{\mu m}\end{array}$ \\
\hline 1 & 0.08333 & -1.38299 & 0.00498 & 0.00893 & 0.29 \\
2 & 0.25 & -0.67449 & 0.00499 & 0.00894 & 0.30 \\
3 & 0.416667 & -0.21043 & 0.00500 & 0.00895 & 0.31 \\
4 & 0.58333 & 0.21043 & 0.00502 & 0.00898 & 0.32 \\
5 & 0.75 & 0.67449 & 0.00503 & 0.00899 & 0.33 \\
6 & 0.91667 & 1.382994 & 0.00509 & 0.00900 & 0.34 \\
\hline
\end{tabular}




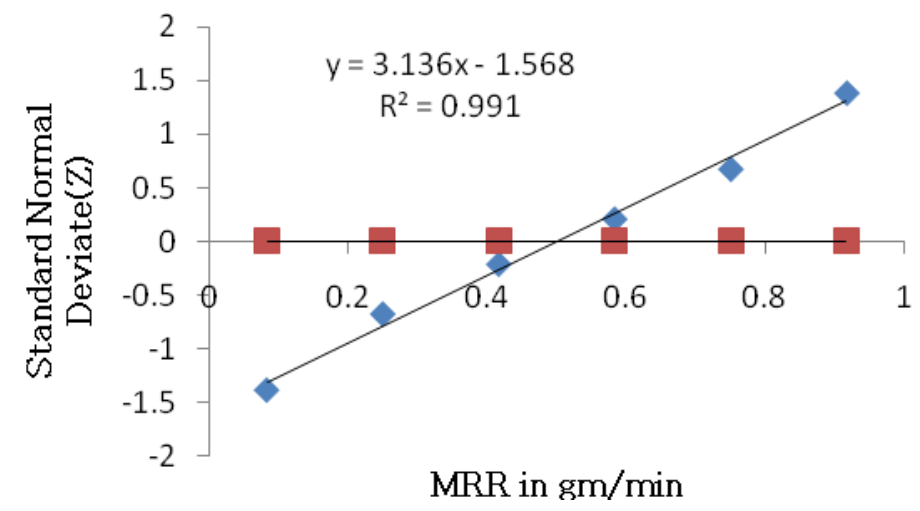

Figure 11: Normal probability curve (at best settings of USM for MRR)

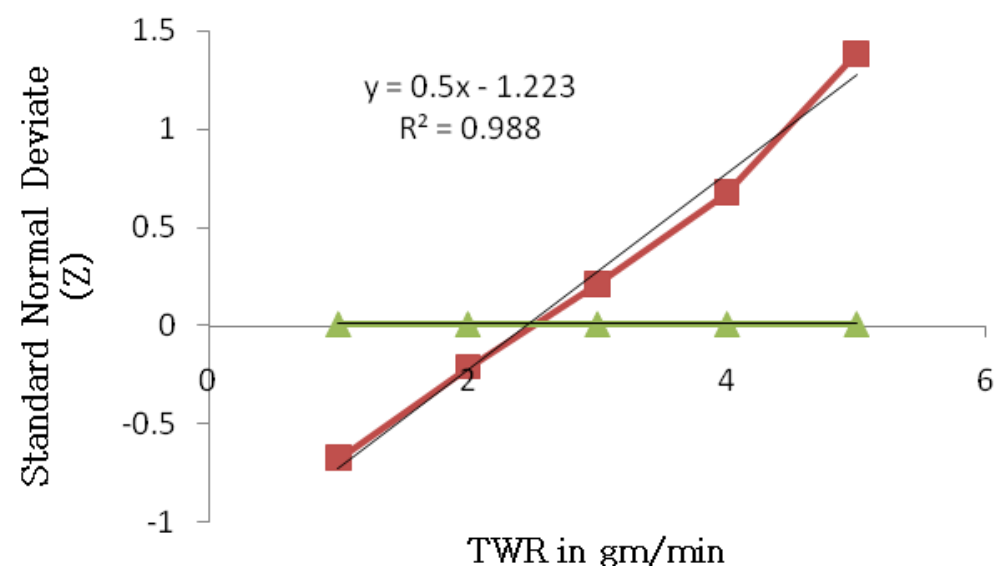

Figure 12: Normal probability curve (at best settings of USM for TWR)



Figure 13: Normal probability curve (at best settings of USM for SR)

Now, again, to understand whether the process is statistically controlled (at other settings of control variables on USM for MRR, TWR and SR) eighteen more samples of titanium alloy pieces were machined based on Table 5. Further run charts of the 
measured values were developed for eighteen sets of experiments corresponding to MRR, TWR and SR. Also the values of the standard normal deviates were calculated using cumulative probability and were arranged in ascending order. For these eighteen sets of observations, $\left|Z_{\mathrm{AB}}\right|$ and $\left|\mathrm{Z}_{\mathrm{UD}}\right|$ are $<\mathrm{Z}_{\text {crit }}$ indicating the existence of a random pattern. So, there are very strong chances that the process is not under statistical control at these settings of the control parameters.

\section{CONCLUSIONS}

The following conclusions may be drawn:

a) As regards to MRR, power rating and type of tool are important factors followed by slurry type.

b) The type of tool and power rating are important factors followed by grit size of the slurry for TWR.

c) The slurry temperature is the most important followed by slurry concentration and type of tool for SR.

d) The model developed shows a close relationship between the experimental observations made otherwise.

e) The adopted procedure is better as a proof of the proposed Taguchi based model and for USM of other grades of titanium alloys, for which the cost of machining is high.

f) Strong possibilities are observed for the process under statistical control as regard to MRR, TWR and SR is concerned at best settings of input parameters for USM of titanium and its alloys, which is not observed for all other settings of input parameters.

\section{ACKNOWLEDGEMENTS}

The author would like to thank Dr. J. S. Khamba, Prof. Mech. Eng. Punjabi Univ. Patiala for technical advice.

\section{REFERENCES}

Benedict, G.F. (1987) Non Traditional Manufacturing Processes. NY: Marcel Dekker.

Devor, R.E., Chang, T. and Sutherland, J.W. (2005) Statistical Quality Design and Control Contemporary Concepts and Methods. 2 ed. NJ: Pearson Prentice-Hall.

Dornfeld, D.A., Kim, J.S., Dechow, H., Hewsow, J. and Chen, L.J. (1999) Drilling burr formation in titanium alloy Ti-6Al-4V. Annals of CIRP, 48(1): 73-76.

Kumar, J. and Khamba, J.S. (2008) An experimental study on ultrasonic machining of pure titanium using designed experiments. Journal of Braz. Soc. of Mech. Sci. \& Eng. 30(3): 231-238.

Kumar, J., Khamba, J.S. and Mohapatra, S.K. (2008) Investigating and Modeling Tool Wear Rate in the Ultrasonic Machining of Titanium. International Journal of Advanced Manufacturing Technology. 41(11-12): 110-1117.

Phadke, M.S. (1989) Quality engineering using robust design. NJ: PTR Prentice-Hall.

Singh, R. (2006) Investigating the machining characteristics of titanium alloys using ultrasonic machining. Ph.D. Thesis, T.I.E.T., Patiala, India. 
Singh, R. and Khamba, J.S. (2003) Silicon carbide slurry effect in ultrasonic assisted drilling of titanium alloy (TITAN15). Journal of Manufacturing Technology Today, 2(7): 08-11.

Singh, R. and Khamba, J.S. (2004) Tool manufacturing technique in ultrasonic drilling machine. Journal of Manufacturing Technology Today, 3(1): 05-07.

Singh, R. and Khamba, J.S. (2006) Ultrasonic machining of titanium and its alloys: A Review. Journal of Material Processing Technology, 173(2): 125-135.

Singh, R. and Khamba, J.S. (2007a) Investigations for ultrasonic machining of titanium and its alloys. Journal of Material Processing Technology, 183 (2-3): 363-367.

Singh, R. and Khamba, J.S. (2007b) Macro-model for ultrasonic machining of titanium and its alloys: designed experiments. Journal of Engineering Manufacture, B2: 221-229.

Singh, R. and Khamba, J.S. (2008) Comparison of slurry effect on machining characteristics of titanium in ultrasonic drilling. Journal of Material Processing Technology, 197(1-3): 200-205.

Singh, R. and Khamba, J.S. (2009a) Mathematical modeling of surface roughness in ultrasonic machining of titanium using Buckingham- $\prod$ approach: A Review. International Journal of Abrasive Technology, 2(1): 03-24.

Singh, R. and Khamba, J.S. (2009b) Mathematical modeling of tool wear rate in ultrasonic machining of titanium. International Journal of Advanced Manufacturing Technology, 43(5-6): 573-580.

Taguchi, G. and Konishi, S. (1987) Orthogonal arrays and linear graphs. Dearborn, MI: ASI Press.

Thoe, T.B., Aspinwall, D.K. and Wise, M.L.H. (1998) Review on ultrasonic machining. International Journal of Machine Tools Manufacture, 38(4): 239255.

Verma, D.R.S.V., Nandagopal, B.G., Srinivasulu, K. and Reddy, S.S. (2003) Effect of predrilled holes on tool life in turning of aerospace titanium alloys. National conference on advances in manufacturing system (AMS-03), Jadavpur University, 42-47. 